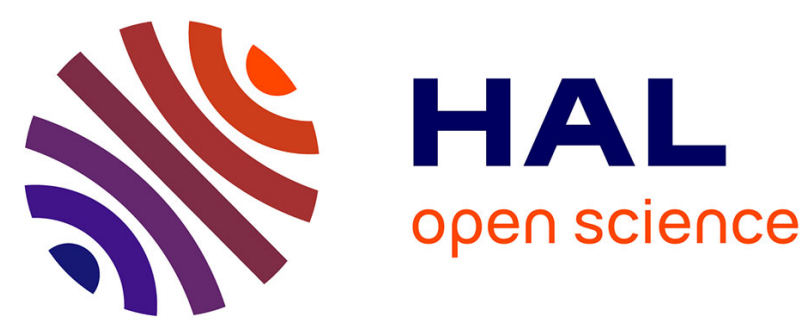

\title{
Correlation of age and hematoma volume in patients with spontaneous lobar intracerebral hemorrhage
} Joji B. Kuramatsu, Roland Sauer, Christoph Mauer, Hannes Lücking, Stephan P. Kloska, Ines-Christine Kiphuth, Dimitre Staykov, Martin Köhrmann, Hagen B. Huttner

\section{To cite this version:}

Joji B. Kuramatsu, Roland Sauer, Christoph Mauer, Hannes Lücking, Stephan P. Kloska, et al.. Correlation of age and hematoma volume in patients with spontaneous lobar intracerebral hemorrhage. Journal of Neurology, Neurosurgery and Psychiatry, 2010, 82 (2), pp.144. 10.1136/jnnp.2010.208439 . hal-00560318

\section{HAL Id: hal-00560318 https://hal.science/hal-00560318}

Submitted on 28 Jan 2011

HAL is a multi-disciplinary open access archive for the deposit and dissemination of scientific research documents, whether they are published or not. The documents may come from teaching and research institutions in France or abroad, or from public or private research centers.
L'archive ouverte pluridisciplinaire HAL, est destinée au dépôt et à la diffusion de documents scientifiques de niveau recherche, publiés ou non, émanant des établissements d'enseignement et de recherche français ou étrangers, des laboratoires publics ou privés. 


\title{
Correlation of age and hematoma volume in patients with spontaneous lobar intracerebral hemorrhage
}

\author{
Joji B. Kuramatsu ${ }^{1}$, Roland Sauer ${ }^{1}$, Christoph Mauer ${ }^{1}$, Hannes Lücking ${ }^{2}$, \\ Stephan P. Kloska ${ }^{2}$, Ines-Christine Kiphuth ${ }^{1}$, Dimitre Staykov ${ }^{1}$, \\ Martin Köhrmann ${ }^{1}$ and Hagen B. Huttner ${ }^{1}$ \\ 1 Department of Neurology, University of Erlangen, Germany \\ 2 Department of Neuroradiology, University of Erlangen, Germany
}

\section{Address for correspondence:}

Dr. H.B. Huttner

Department of Neurology

University of Erlangen

Schwabachanlage 6

91054 Erlangen

Germany

Phone: $\quad+4991318534563$

Fax: $\quad+4991318536597$

Email: $\quad$ hagen.huttner@uk-erlangen.de 


\section{Acknowledgements}

We would like to thank Professor Peter D. Schellinger and Dr. Elisabeth Pauli (Department of Neurology, University of Erlangen, Germany) for helping with the statistics. The study was not funded.

\section{Conflict of Interest}

There is no conflict of interest.

\section{Contributions}

J.B.K., M.K., and H.B.H designed the study and wrote the manuscript. J.B.K., R.S., C.M., I.C.K., and D.S. obtained clinical data by reviewing institutional databases and the patient's medical charts. H.L. and S.K. analyzed the images and obtained all neuroradiological data. J.B.K., R.S., I.C.K., and D.S. contacted all patients and obtained the pre-admission- and functional outcome-data of the analyzed patients. All authors have read the manuscript, agree with the contents, and approved the final version of the manuscript.

\section{Licence for Publication}

The Corresponding Author has the right to grant on behalf of all authors and does grant on behalf of all authors, an exclusive licence (or non exclusive for government employees) on a worldwide basis to the BMJ Publishing Group Ltd to permit this article (if accepted) to be published in JNNP and any other BMJPGL products and sublicences such use and exploit all subsidiary rights, as set out in our licence.

(http://group.bmj.com/products/journals/instructions-for-authors/licence-forms) 
Full title

Cover title

Original contribution

Abstract word count

Number of tables

Number of figures

Number of references

Key words
Correlation of age and hematoma volume in patients with

spontaneous lobar intracerebral hemorrhage

Parameters related to lobar ICH

2.876 words

264 words

5

1

38

spontaneous intracerebral hemorrhage (ICH)

cerebral amyloid angiopathy

lobar ICH

hematoma volume

age-volume correlation 


\begin{abstract}
Background

Lobar intracerebral hemorrhage $[\mathrm{LH}]$ is gaining importance in the ageing population, however there are only limited data regarding specific clinical characteristics and risk factors of elderly patients with $\mathrm{LH}$.
\end{abstract}

\title{
Methods
}

This retrospective analysis of patients with spontaneous supratentorial hemorrhage included 174 consecutive patients (78 $\mathrm{LH}$ and 96 deep $\mathrm{ICH}[\mathrm{DH}])$. Clinical data including the preadmission status, neuroradiological findings, initial presentation, treatment, and outcome were evaluated through institutional databases, patient's medical charts and by mailed questionnaires. Logistic regression analyses were calculated for initial parameters predisposing $\mathrm{LH}$ and for treatment and outcome parameters associated with $\mathrm{LH}$.

\section{Results}

Age-stratified volume analysis revealed increasing hematoma volumes for LH ( $\leq 70 \mathrm{y}: 26.2 \mathrm{ml}$, 70-80y: 37ml, >80y: 61.3ml), whereas DH showed no relation between volume and age (<70y: 10.1ml, 70-80y: 23.2ml, >80y: 12.1ml). DH patients had significantly higher HbA1c levels. Post-ICH seizures were more frequent after LH. Logistic regression analyses identified the parameters: age, hematoma volume, and post-ICH seizures to be associated with $\mathrm{LH}$, whereas intraventricular hemorrhage, extraventricular drainages and elevated $\mathrm{HbA} 1 \mathrm{c}$ were related to $\mathrm{DH}$. 


\section{Conclusion}

Hematoma volumes are substantially increasing in LH patients that are older than 70 years. Pathologic HbA1c levels are significantly associated and predisposing for DH. These findings further support the ongoing debate of different disease entities for supratentorial ICH (i.e. association of cerebral amyloid angiopathy and lobar ICH versus diabetes induced atherosclerosis in deep ICH). Future studies should focus on identifying specific pathologic characteristics and risk factors for both bleeding sites to implement specific preventive measures, i.e. amyloid angiopathy modulating therapies for LH, and to avoid risk factors that are specific for each hemorrhage location. 


\section{Introduction}

Spontaneous intracerebral hemorrhage $[\mathrm{ICH}]$ is one of the most devastating cerebrovascular diseases with a 30-day mortality rate up to $35-52 \%$, and poor clinical outcome leaving only $20 \%$ of patients functionally independent $(\mathrm{mRS}<3)$ at 6 months $(1,2)$. Generally, the incidence of ICH among first ever strokes is slightly decreasing and ranges from $10-15 \%$. however the absolute amount of ICH has increased over the last 10 years and its rate is expected to double by the year 2050 (3-5). However, among ethnic populations there are differences in incidence as well as hemorrhage location (6). Deep ICH $[\mathrm{DH}]$ is the most common location (36-67\%), followed by lobar ICH [LH] (15-52\%), cerebellar (7-11\%) and brainstem hemorrhage (4-9\%) (6-8). Identified risk factors for all ICH are hypertension, male sex, age, alcohol abuse, and other less established risk factors are smoking, diabetes, anemia, higher fibrinogen levels, lower LDL and triglycerides as well as renal and hepatic insufficiency $(5,9-11)$.

The major consentaneous risk factor for LH is cerebral amyloid angiopathy [CAA] (12). Incidence rates of CAA are strongly age dependent, being only $2.3 \%$ for patients younger than 75 years of age, but being $8 \%$ for $75-84$ year-old-, and $12.1 \%$ for over 85 year-old patients, respectively, while post mortem examinations of ICH patients revealed incidences as high as $23 \%-54 \%(12,13)$. Overall, 30 day mortality after LH ranges from $11-30 \%$, and up to $57 \%$ at one year, with the best prognosis for patients with smaller hematoma volume and better levels of consciousness on admission $(12,14)$. A superficial location and less intraventricular hemorrhage $[\mathrm{IVH}]$ has also been reported favorable to outcome, whereas older age of patients is less favourable (15). LH has been shown to be associated with higher rates of recurrent $\mathrm{ICH}$, higher occurrence of post stroke seizures, and an increased incidence of LH in the elderly population has been proposed $(4,5,16)$. Given these specific features and 
in light of the divergent risk profile, $\mathrm{LH}$ has been assumed to reflect a different disease entity $(5)$.

The majority of previous studies reported only on small numbers of elderly patients with supratentorial $\mathrm{ICH}$, thus representing limited data regarding their clinical characteristics and vascular risk factors (11). Considering the growing relevance of LH in ageing populations, we compared a broad spectrum of patient characteristics including pre-admission status, past medical and medication history, clinical, neuroradiological and laboratory parameters as well as treatment and functional outcome among both supratentorial hemorrhage sites. Our aim was to further specify characteristics of a lobar location of ICH in elderly patients. 


\section{Methods}

\section{$\underline{\text { Patient selection }}$}

This retrospective study included consecutive patients with supratentorial ICH who were admitted to the neurocritical care or stroke-unit of the Department of Neurology, University of Erlangen, from January 2007 until February 2009. The analysis was based on our institutional database into which all relevant clinical and neuroradiological data of ICH patients were included. From 236 patients with the diagnosis of ICH we excluded posterior fossa hematomas $(n=48)$, and by definition did not include patients with secondary $\mathrm{ICH}$, i.e. $\mathrm{ICH}$ related to oral anticoagulant therapy, trauma, tumor, arteriovenous malformations, cerebral venous thrombosis, subarachnoid hemorrhage, or with acute thrombolysis or coagulopathy with platelet counts below 50.000/ $\mu 1$. Moreover, we excluded those patients who were lost to follow-up ( $\mathrm{n}=14)$. Hence, 174 patients (78 $\mathrm{LH}$ and $96 \mathrm{DH}$ ) of central European descent remained for analysis.

\section{$\underline{\text { Parameter acquisition }}$}

Clinical presentation; All in-hospital parameters (GCS, NIHSS, ICH-score, body temperature, and mean arterial blood pressure) were obtained by reviewing the patient's medical charts, emergency protocols, and institutional databases.

Laboratory parameters; Data were obtained by reviewing the patient's medical charts and institutional databases. Data are presented as continuous variables. Initial on admission data are presented.

Pre-admission status and past medical history; Data of patients prior to admission were obtained by a mailed standardized questionnaire. Whenever this questionnaire did not return within 6 weeks, a semi-quantitative phone interview was conducted with patients, or their closest relatives, respectively. Telephone interviews were performed by four physicians 
(J.B.K., R.S., I.C.K., D.S.) who were trained and certified for data collection on disability and quality of life. Written or oral consent was obtained from all patients or their relatives. The pre-admission data consisted of: body mass index, history of ischemic or hemorrhagic stroke, history of epileptic seizures, history of cardiac event (myocardial infarction or peripheral arterial embolism), use of nicotine ( $>2$ pack years), alcohol abuse (defined as $>80 \mathrm{~g}$ ethanol/day), intake of aggregation inhibitors, intake of statines, diagnosis of hypercholesterolemia, diagnosis of arterial hypertension according to established criteria (17), and diagnosis of diabetes mellitus (18).

In-hospital treatment; Parameters were obtained by reviewing the patient's medical charts. Treatment data was: Need of ventilation (in days), hospital length of stay (in days), requirement of external ventricular drainage [EVD] (for occlusive hydrocephalus (19)), or lumbar drainages (for post-hemorrhagic communicating hydrocephalus (20)), intraventricular fibrinolysis using rt-PA (21), diagnosis of pneumonia, and sepsis according to established criteria $(22,23)$.

Outcome findings; Mortality and functional outcome data were obtained by mailed questionnaires and structured phone interviews, as appropriate, as described above for preadmission data. The functional outcome was assessed after 3 months and 1 year (73\% by filled in questionnaires and $27 \%$ by telephone interviews), and was evaluated using the modified Rankin scale [mRS] (24). Favorable outcome was defined as mRS 0-2. Mortality was evaluated at 3 months and 12 months after ICH. Post ICH-seizures were scored if patients developed focal or generalized seizures $(\geq 2)$ within one year after stroke (25).

\section{Imaging}

Diagnosis of ICH was made immediately after hospital admission by either CT (SIEMENS Somatom Volume Zoom, Erlangen, Germany) or MRI (SIEMENS Sonata, 1.5 Tesla, Erlangen, Germany). Two neuroradiologists (H.L. and S.K.) who were blinded to all clinical 
data reviewed the scans independently in randomized order. For all cases in which there was discrepancy regarding neuroradiological parameters a second consensus analysis was made. Time from symptom onset to intial imaging was between $0-6 \mathrm{~h}, 86.9 \%$ of patients had intital CT and $13.1 \%$ patients MRI scans. All patients received follow-up imaging within $48 \mathrm{~h}$. Location of hemorrhage was defined as lobar versus deep (latter including thalamic hematomas). Hematoma volume was calculated according to the formula of ellipsoids $(\mathrm{ABC} / 2)$ (26). IVH or subdural extensions were not taken into account for volume measurement. IVH was documented and scored using the Graeb score summation (27). Hematoma growth was defined as an increase of intraparenchymal hemorrhage volume $>33 \%$ as measured by image analysis on follow-up CT or MRI (28). Midline shift was measured on initial imaging at the site of maximal deflection in $\mathrm{mm}$.

\section{$\underline{\text { Statistical Analysis }}$}

Statistical Analysis was performed with the SPSS 17.0 software package (www.spss.com) and Statview version 5.0 (www.jmp.com). The significance level was set at $\alpha=0.05$. Statistical tests were two-sided. Data distribution was assessed with the Kolmogorov-Smirnov test. Normally distributed data are presented as mean \pm SD and was compared using the Student Ttest. Other data are presented as median with IQR $\left(25^{\text {th }}-75^{\text {th }}\right.$ percentile $)$, and were compared using the Mann-Whitney-U-test. The Pearson $\chi 2$ - or Fisher's exact tests were used to analyse frequency distributions of categorized variables between $\mathrm{LH}$ versus $\mathrm{DH}$. The correlation of age and hematoma volume with hemorrhage location was shown graphically using the Whisker-Box-plot and locally weighted scatterplot smoothing [LOWESS] with a $=0.25-0.5$ and a tension $=66$. Regarding the parameter age, we a priori decided to trichotomize the patients into those younger than 70 years, between 70 and 80 years, and older than 80 years (29). One univariate logistic regression analysis was calculated to determine parameters that were associated with LH. Two stepwise forward inclusion multivariable logistic regression 
models were calculated for parameters that were significant or showed a trend in the univariate analysis $(\mathrm{p}<0.1)$ with lobar $\mathrm{ICH}$ as the dependent variable. The first multivariate model was calculated with parameters that were predisposing for LH (table 4 a-d). A second multivariate regression model was calculated to identify those parameters arising not until the course of treatment that were independently related to LH (table 4 e). 


\section{Results}

The demographic, pre-admission and neuroradiological characteristics of all patients are shown in table 1 . The time to hospital arrival as well as the chosen imaging modality did not differ between patients with lobar and deep ICH. The clinical and laboratory findings on admission are given in table 2.

Mean age was 70.2 years (range $=35-98 y$ ). The comparison of age between lobar and deep hemorrhage revealed significant overall differences ( 73.8 versus 67.6 years), even more when focussing on age stratified patients (i) $\leq 70 \mathrm{y}$, (ii) $>70 \mathrm{y}$, and (iii) $>80 \mathrm{y}$, respectively (table 1 ). LH was significantly more frequent among the older age group (i.e. $>70 y, \mathrm{LH}(\mathrm{n}=52), \mathrm{DH}$ $(\mathrm{n}=39) ; \mathrm{p}<0.001)$. Lesion volume was significantly higher in $\mathrm{LH}$ than in $\mathrm{DH}$ (42.7 versus 11.9 $\mathrm{ml})$. The correlation of age, volume and lesion site is shown in figure 1 and displays a substantial volume increase for LH patients with a take off at $>70$ years. In contrast DH patients showed no correlation of volume and age. A history of prior hemorrhagic stroke was significantly more often with LH. IVH as well as the Graeb score was significantly higher and more frequent in $\mathrm{DH}(\mathrm{p}<0.001)$.

Significant laboratory findings in LH patients were higher HDL-values $(p=0.043)$ as well as lower HbA1c levels $(\mathrm{p}=0.042)$. Given the significance of HbA1c, a dichotomized analysis revealed significantly less patients with a pathologically elevated HbAlc (i.e. >6.5\%; LH (9/78), vs. DH (31/96), $\mathrm{p}<0.01)$.

Treatment procedures and the outcome findings are given in table 3. LH patients required neurocritical care for a significantly shorter period of time $(\mathrm{p}=0.046)$ and were less frequently mechanically ventilated $(\mathrm{p}=0.015)$. As shown in table 1 , patients with LH suffered less often 
from IVH, hence rarely required placement of an EVD $(\mathrm{p}<0.001)$. In this regard DH patients required intraventricular fibrinolysis more often $(\mathrm{p}<0.001)$ as well as lumbar drainage placement $(\mathrm{p}<0.001)$. Moreover, complications like pneumonia, and sepsis, were more commonly appreciated with $\mathrm{DH}(\mathrm{p}=0.049$, and $\mathrm{p}=0.024)$. Mortality rates and the functional outcome measures revealed no significant differences among both groups. The only outcome difference for $\mathrm{LH}$ was the development of post-ICH seizures $(\mathrm{p}=0.028)$.

The univariate associations of significant parameters or those showing a trend with LH are listed in table 4. The multivariate logistic regression models are shown in table 5. With respect to pre-admission status and initial presentation the parameters (i) age and (ii) hematoma volume were independently predisposing for LH, whereas (iii) presence of IVH, and (iv) elevated HbA1c levels were inversely correlated (table 5a). Regarding the regression analysis for treatment and outcome the incidence of post-ICH seizures was independently related to $\mathrm{LH}$, whereas requirement of an EVD was inversely associated (table 5b). 


\section{Discussion}

In the present study we compared clinical, neuroradiological, and laboratory parameters of patients with supratentorial hemorrhage to identify specific parameters that were independently related to LH. Key findings of LH were: (i) increasing age resulted in an increase of hematoma volume, and (ii) pathologically elevated levels of $\mathrm{HbA1c}$ were less common. Moreover, (iii) the frequency of IVH with consecutive need of EVD was lower, and (iv) the rate of post-ICH seizures higher in patients with LH. The following aspects emerged from the data.

The present study discovered a previously unnoticed age-volume correlation in LH. Each parameter, older age and greater hematoma volume, has been separately described to be independently associated with LH. However there were only limited data on the exact correlation of these factors with various patient characteristics, radiological features and outcome. With respect to increasing hematoma volumes in the elderly LH patient, one has to refer to CAA, as the strongest age dependent risk factor for $\mathrm{LH}(4,12,15,16)$. CAA is defined by the deposition of $\beta$-amyloid protein in the media and adventitia of vessels of the cortex and leptomeninges (13). Therefore the finding of larger hematoma volumes in older patients with LH could be based on greater vascular fragility because of a higher prevalence of severe angiopathy with fibrinoid necrosis $(13,16)$. In addition, a more pronounced parenchymal atrophy of the cerebral lobes with less consecutive tamponade effect of the hematoma itself and hence greater volumes, might also be attributable in elderly patients. We could not find significant differences for other factors influencing volume, such as the use of aggregation inhibition, hepatic dysfunction, coagulation parameters, or prevalence of hypertension amongst $\mathrm{DH}$ and $\mathrm{LH}$. With respect to hypertension as the strongest independent risk factor for $\mathrm{ICH}(4,30)$, we were not able to elucidate any relationship with $\mathrm{LH}$, neither a 
different prevalence, nor greater hematoma volumes, nor more frequent hematoma growth on control scans. Therefore the findings presented here may support the idea of previous studies that arterial hypertension should be considered as a secondary side finding in the elderly LH patient, and not as primary causative factor for LH. If correct this which is in line with the hypothesis of different disease entities as the primary cause for DH and LH can be prospectively tested in the future $(4,11,12,31)$

This aspect of different disease entities seems also supported by the finding of significantly elevated HbA1c levels in DH patients. Evaluation of other previously noted cerebrovascular risk factors did not show differences amongst our patient cohort. Special attention should be given to $\mathrm{HbA} 1 \mathrm{c}$ as a diagnostic and surveillance marker $(18,32)$. As glycosylated hemoglobin can be considered a widely accepted parameter for the assessment of an atherosclerotic risk profile $(5,18,32)$, its elevation may also be relevant as driving co-factor for $\mathrm{DH}$. Given the difficulty of assessing prior history of long standing diabetes and compliant drug taking behaviour (33), and in light of diabetes as a already proposed weak risk factor for ICH in general (5), patients with elevated HbA1c levels should be screened for further atherosclerotic progression and risk factors that are predisposing for DH to optimize primary prevention of $\mathrm{ICH}$.

IVH in supratentorial hemorrhage occurs more frequently with larger hematoma volumes and is influenced by hemorrhage location as the basal ganglia and thalamus are located more closely to the ventricular system $(5,11)$ In line with these studies, IVH was also less frequently associated with LH in our series (34), therefore resulting in fewer placements of EVD, LD and use of intraventricular fibrinolysis $(20,35)$. IVH has previously been shown to be related to a higher mortality and poorer functional outcome (35), however, given the finding in LH with fewer IVH, we could not show significant outcome differences between 
patients with DH and LH. This may be based on the average older age of LH patients and potentially more co-morbidities and larger hematoma volumes in LH. Hence, it appears plausible that those two predictors (IVH \& volume) were counterbalancing functional outcome of LH versus DH. Additionally, patients with IVH received an aggressive treatment regimen including EVD, intraventricular fibrinolysis, and lumbar drainages, which also could have contributed to an equivalent mortality and functional outcome after supratentorial hemorrhage $(20,35,36)$.

Regarding the development of seizures after spontaneous $\mathrm{ICH}$, the reported incidences range between $2.8-18.7 \%$, and predictors for their development are cortical involvement, subdural hematoma and hematoma volume (37). In line with these studies, LH was strongly associated with the occurrence of seizures. However, hematoma volume was not associated with an increased frequency of seizures in our series (data not shown). Interestingly, patients who received EVD placement did not reveal an increased rate of seizures as compared to patients without EVD, irrespective of hematoma site. Although based on a small number of patients who received an EVD $(n=45)$, this finding could indicate that cortical trauma caused by an EVD may not lead to a decreased seizure threshold. Furthermore, we did not detect outcome differences among patients with and without post-ICH seizures $(4,30,37)$.

Our study has certain limitations: (i) due to the nature of this retrospective, single-center investigation, the patient number of $n=174$ appears rather small to draw definite conclusions on patient characteristics. (ii) No "gold standard" test for CAA such as autopsy was applied to all subjects. (iii) Confirmation of the duration of diabetes, arterial hypertension, and the extent of subsequent atherosclerosis in brain and whole body was not evaluated. (iv) The impact of exclusion of both posterior fossa bleedings and ICH related to oral anticoagulants on the findings is unknown. (v) The mailed questionnaire was filled-out by patients, their relatives or 
legal attorneys and may have been answered wrongly with respect to the time-point of followup and the validity of mRS estimation (38). (vi) As we did not focus on first ever ICH only, but included patients with recurrent $\mathrm{ICH}$, this selection bias might have impacted hematoma volume at presentation as well as functional outcome. (vii) Finally results may have been biased by 14 patients who were lost to follow-up.

Concluding the findings of our study, we identified a highly significant age-volume correlation in elderly patient with LH only, whereas pathologically elevated HbA1c levels were attributable to basal ganglia and thalamus bleedings. In light of a still the tremendous disease burden of ICH and its growing relevance in the aging population, future studies should focus on (i) establishing novel CAA-modulating treatment strategies and (ii) further attempts to definitively classify LH (as amyloid-angiopathic disease) and (iii) DH (as atherosclerotic disease). If this classification proves correct, then treating these two supratentorial hemorrhage locations more specifically with respect to different risk factors and patient characteristics could be very important. 


\section{References}

1. Tuhrim S, Dambrosia JM, Price TR, Mohr JP, Wolf PA, Heyman A, et al. Prediction of intracerebral hemorrhage survival. Ann Neurol. 1988 Aug;24(2):258-63.

2. Broderick JP, Brott TG, Duldner JE, Tomsick T, Huster G. Volume of intracerebral hemorrhage. A powerful and easy-to-use predictor of 30-day mortality. Stroke. 1993 Jul;24(7):987-93.

3. Lovelock CE, Molyneux AJ, Rothwell PM. Change in incidence and aetiology of intracerebral haemorrhage in Oxfordshire, UK, between 1981 and 2006: a population-based study. Lancet Neurol. 2007 Jun;6(6):487-93.

4. Qureshi AI, Mendelow AD, Hanley DF. Intracerebral haemorrhage. Lancet. 2009 May 9;373(9675):1632-44.

5. Qureshi AI, Tuhrim S, Broderick JP, Batjer HH, Hondo H, Hanley DF. Spontaneous intracerebral hemorrhage. N Engl J Med. 2001 May 10;344(19):1450-60.

6. Flaherty ML, Woo D, Haverbusch M, Sekar P, Khoury J, Sauerbeck L, et al. Racial variations in location and risk of intracerebral hemorrhage. Stroke. 2005 May;36(5):934-7.

7. Christensen MC, Broderick J, Vincent C, Morris S, Steiner T. Global Differences in Patient Characteristics, Case Management and Outcomes in Intracerebral Hemorrhage: The Factor Seven for Acute Hemorrhagic Stroke (FAST) Trial. Cerebrovasc Dis. 2009 May 20;28(1):55-64.

8. Maia LF, Vasconcelos C, Seixas S, Magalhaes R, Correia M. Lobar brain hemorrhages and white matter changes: Clinical, radiological and laboratorial profiles. Cerebrovasc Dis. 2006;22(2-3):155-61.

9. Kumar MA, Rost NS, Snider RW, Chanderraj R, Greenberg SM, Smith EE, et al. Anemia and hematoma volume in acute intracerebral hemorrhage. Crit Care Med. 2009 Apr;37(4):1442-7.

10. Bos MJ, Koudstaal PJ, Hofman A, Breteler MM. Decreased glomerular filtration rate is a risk factor for hemorrhagic but not for ischemic stroke: the Rotterdam Study. Stroke. 2007 Dec;38(12):3127-32.

11. Sturgeon JD, Folsom AR, Longstreth WT, Jr., Shahar E, Rosamond WD, Cushman M. Risk factors for intracerebral hemorrhage in a pooled prospective study. Stroke. 2007 Oct;38(10):2718-25.

12. Smith EE, Eichler F. Cerebral amyloid angiopathy and lobar intracerebral hemorrhage. Arch Neurol. 2006 Jan;63(1):148-51. 
13. Ritter MA, Droste DW, Hegedus K, Szepesi R, Nabavi DG, Csiba L, et al. Role of cerebral amyloid angiopathy in intracerebral hemorrhage in hypertensive patients. Neurology. 2005 Apr 12;64(7):1233-7.

14. Flaherty ML, Haverbusch M, Sekar P, Kissela B, Kleindorfer D, Moomaw CJ, et al. Long-term mortality after intracerebral hemorrhage. Neurology. 2006 Apr 25;66(8):1182-6.

15. Patel PV, FitzMaurice E, Nandigam RN, Auluck P, Viswanathan A, Goldstein JN, et al. Association of subdural hematoma with increased mortality in lobar intracerebral hemorrhage. Arch Neurol. 2009 Jan;66(1):79-84.

16. O'Donnell HC, Rosand J, Knudsen KA, Furie KL, Segal AZ, Chiu RI, et al. Apolipoprotein E genotype and the risk of recurrent lobar intracerebral hemorrhage. $\mathrm{N}$ Engl $\mathbf{J}$ Med. 2000 Jan 27;342(4):240-5.

17. Reeves RA. The rational clinical examination. Does this patient have hypertension? How to measure blood pressure. JAMA. 1995 Apr 19;273(15):1211-8.

18. Report of the Expert Committee on the Diagnosis and Classification of Diabetes Mellitus. Diabetes Care. 1997 Jul;20(7):1183-97.

19. van Gijn J, Hijdra A, Wijdicks EF, Vermeulen M, van Crevel H. Acute hydrocephalus after aneurysmal subarachnoid hemorrhage. J Neurosurg. 1985 Sep;63(3):355-62.

20. Huttner HB, Nagel S, Tognoni E, Kohrmann M, Juttler E, Orakcioglu B, et al. Intracerebral hemorrhage with severe ventricular involvement: lumbar drainage for communicating hydrocephalus. Stroke. 2007 Jan;38(1):183-7.

21. Huttner HB, Tognoni E, Bardutzky J, Hartmann M, Kohrmann M, Kanter IC, et al. Influence of intraventricular fibrinolytic therapy with rt-PA on the long-term outcome of treated patients with spontaneous basal ganglia hemorrhage: a case-control study. Eur J Neurol. 2008 Apr;15(4):342-9.

22. Tejerina E, Esteban A, Fernandez-Segoviano P, Frutos-Vivar F, Aramburu J, Ballesteros D, et al. Accuracy of clinical definitions of ventilator-associated pneumonia: Comparison with autopsy findings. J Crit Care. 2009 Jul 8.

23. Muckart DJ, Bhagwanjee S. American College of Chest Physicians/Society of Critical Care Medicine Consensus Conference definitions of the systemic inflammatory response syndrome and allied disorders in relation to critically injured patients. Crit Care Med. 1997 Nov;25(11):1789-95.

24. Rankin J. Cerebral vascular accidents in patients over the age of 60. I. General considerations. Scott Med J. 1957 Apr;2(4):127-36. 
25. Kilpatrick CJ, Davis SM, Tress BM, Rossiter SC, Hopper JL, Vandendriesen ML. Epileptic seizures in acute stroke. Arch Neurol. 1990 Feb;47(2):157-60.

26. Kothari RU, Brott T, Broderick JP, Barsan WG, Sauerbeck LR, Zuccarello M, et al. The ABCs of measuring intracerebral hemorrhage volumes. Stroke. 1996 Aug;27(8):1304-5.

27. Graeb DA, Robertson WD, Lapointe JS, Nugent RA, Harrison PB. Computed tomographic diagnosis of intraventricular hemorrhage. Etiology and prognosis. Radiology. 1982 Apr;143(1):91-6.

28. Brott T, Broderick J, Kothari R, Barsan W, Tomsick T, Sauerbeck L, et al. Early hemorrhage growth in patients with intracerebral hemorrhage. Stroke. 1997 Jan;28(1):1-5.

29. Woo D, Sekar P, Chakraborty R, Haverbusch MA, Flaherty ML, Kissela BM, et al. Genetic epidemiology of intracerebral hemorrhage. J Stroke Cerebrovasc Dis. 2005 NovDec;14(6):239-43.

30. Broderick J, Connolly S, Feldmann E, Hanley D, Kase C, Krieger D, et al. Guidelines for the management of spontaneous intracerebral hemorrhage in adults: 2007 update: a guideline from the American Heart Association/American Stroke Association Stroke Council, High Blood Pressure Research Council, and the Quality of Care and Outcomes in Research Interdisciplinary Working Group. Stroke. 2007 Jun;38(6):2001-23.

31. Flaherty ML, Woo D, Broderick J. The incidence of deep and lobar intracerebral hemorrhage in whites, blacks, and Hispanics. Neurology. 2006 Mar 28;66(6):956-7; author reply -7 .

32. Mitka M. Hemoglobin A1c poised to become preferred test for diagnosing diabetes. JAMA. 2009 Apr 15;301(15):1528.

33. Mol A. Living with diabetes: care beyond choice and control. Lancet. 2009 May 23;373(9677):1756-7.

34. Huttner HB, Kohrmann M, Tognoni E, Juttler E, Richter G, Dorfler A, et al. Clinical severity predicts time to hospital admission in patients with spontaneous intracerebral hemorrhage. Cerebrovasc Dis. 2008;25(6):533-8.

35. Hanley DF. Intraventricular hemorrhage: severity factor and treatment target in spontaneous intracerebral hemorrhage. Stroke. 2009 Apr;40(4):1533-8.

36. Staykov D, Huttner HB, Struffert T, Ganslandt O, Doerfler A, Schwab S, et al. Intraventricular Fibrinolysis and Lumbar Drainage for Ventricular Hemorrhage. Stroke. 2009 Aug 13. 
37. Claassen J, Jette N, Chum F, Green R, Schmidt M, Choi H, et al. Electrographic seizures and periodic discharges after intracerebral hemorrhage. Neurology. 2007 Sep 25;69(13):1356-65.

38. Banks JL, Marotta CA. Outcomes validity and reliability of the modified Rankin scale: implications for stroke clinical trials: a literature review and synthesis. Stroke. 2007 Mar;38(3):1091-6. 


\section{Table and Figure legends}

Table 1. Demographic, past medical history, and neuroradiologic characteristics. Significant parameters are expressed in bold.

Table 2. Initial clinical presentation and baseline laboratory findings.

Figure 1. Correlation of age and hematoma volume, categorized according to lesion site. (A) Box plot (median, IQR, $75^{\text {th }}-25^{\text {th }}$ percentile) and (B, C) LOWESS (tension $=66)$.

Table 3. In-hospital therapy and outcome findings.

Table 4. Univariate regression analysis for identification of parameters associated with LH. (a) Demographic characteristics and past medical history, (b) neuroradiologic data, (c) initial clinical presentation, (d) baseline laboratory data, (e) in-hospital treatment and outcome findings. Data are calculated as continuous or categorizes variables (see tables 1-3). All parameters given in table 1-3. were analyzed univariately. For reasons of simplification only significant parameters or those showing a trend $(\mathrm{p}<0.1)$ are displayed.

Table 5. Multivariate logistic regression models. (A) Predictors for LH (table 4 a-d). (B) Analysis of treatment and outcome parameters that were univariately related to LH (table 4 e). Variables that remained independently related to $\mathrm{LH}(\mathrm{p}<0.05)$ are expressed in bold. 
Table 1.

\begin{tabular}{|c|c|c|c|c|}
\hline $\begin{array}{l}\text { Total ICH } \\
(\mathrm{n}=174)\end{array}$ & & $\begin{array}{l}\text { Lobar ICH } \\
(\mathrm{n}=78)\end{array}$ & $\begin{array}{l}\text { Deep ICH } \\
(\mathbf{n}=96)\end{array}$ & $p$-value \\
\hline Age $($ mean \pm SD $)$ & & $73.8 \pm 10.7$ & $67.6 \pm 11.3$ & $<0.001$ \\
\hline age $\leq 70 y$ & & $26(33.3 \%)$ & $57(59.4 \%)$ & 0.001 \\
\hline age $>70 y$ & & $52(66.7 \%)$ & $39(40.6 \%)$ & $<0.001$ \\
\hline age $>80 y$ & & $22(28.2 \%)$ & $12(12.5 \%)$ & 0.012 \\
\hline Female & & $37(47.4 \%)$ & $48(50,0 \%)$ & 0.762 \\
\hline \multicolumn{5}{|l|}{ Prior admission status } \\
\hline \multicolumn{5}{|l|}{$\underline{\text { \& past medical history }}$} \\
\hline BMI (mean, \pm SD) & & $26.1 \pm 5.1$ & $27.4 \pm 5.7$ & 0.132 \\
\hline HTN & & $54(65.4 \%)$ & $72(75,0 \%)$ & 0.396 \\
\hline Hypercholesterolemia & & $29(37.1 \%)$ & $26(27.1 \%)$ & 0.190 \\
\hline Diabetes & & $14(17.9 \%)$ & $16(16.6 \%)$ & 0.574 \\
\hline Ischemic stroke & & $18(23.1 \%)$ & $13(13.5 \%)$ & 0.076 \\
\hline Hemorrhagic stroke & & $17(22.1 \%)$ & $2(2.1 \%)$ & $<0.001$ \\
\hline Cardiac event & & $8(10.3 \%)$ & $7(7.3 \%)$ & 0.335 \\
\hline Aspirin use & & $31(39.7 \%)$ & $32(33.3 \%)$ & 0.380 \\
\hline Statine use & & $21(26.9 \%)$ & $19(19.8 \%)$ & 0.265 \\
\hline Alcohol abuse & & $26(33.3 \%)$ & $36(37.5 \%)$ & 0.566 \\
\hline Smoking & & $30(38.5 \%)$ & $38(39.6 \%)$ & 0.887 \\
\hline Epilepsy & & $4(5.1 \%)$ & $1(1.0 \%)$ & 0.207 \\
\hline \multicolumn{5}{|l|}{ Neuroradiologic data } \\
\hline Lesion volume $\left[\mathrm{cm}^{3}\right]$ & (median, IQR) & $42.7(16.1-72.1)$ & $11.9(3.1-37.3)$ & $<0.001$ \\
\hline Vol. for age $\leq 70 \mathrm{y}\left[\mathrm{cm}^{3}\right]$ & (median, IQR) & $26.2(9.1-58.6)$ & $10.1(3.1-26.9)$ & 0.028 \\
\hline Vol. for age $>70 \mathrm{y}\left[\mathrm{cm}^{3}\right]$ & (median, IQR) & $37.0(17.6-86.7)$ & $23.2(4.7-49.6)$ & 0.001 \\
\hline Vol. for age $>80 \mathrm{y}\left[\mathrm{cm}^{3}\right]$ & (median, IQR) & $61.3(30.1-106.3)$ & $12.1(2.9-30.1)$ & 0.008 \\
\hline Left hemisphere & & $46(59.0 \%)$ & $49(51.1 \%)$ & 0.296 \\
\hline IVH & & $26(30.9 \%)$ & $58(69.0 \%)$ & 0.001 \\
\hline Graeb score & (median, IQR) & $0(0-2)$ & $3(0-10)$ & $<0.001$ \\
\hline Hematoma growth & & $8(10.3 \%)$ & $10(10.4 \%)$ & 0.999 \\
\hline Midline shift [mm] & (median, IQR) & $0(0-6.8)$ & $2(0-7.3)$ & 0.288 \\
\hline
\end{tabular}


Table 2.

\begin{tabular}{|c|c|c|c|}
\hline $\begin{array}{l}\text { Total } \\
(n=174)\end{array}$ & $\begin{array}{l}\text { Lobar ICH } \\
(n=78)\end{array}$ & $\begin{array}{l}\text { Deep ICH } \\
(n=96)\end{array}$ & p-value \\
\hline & Median, (IQR) & Median, (IQR) & \\
\hline GCS & $14(5-15)$ & $12(5-15)$ & 0.297 \\
\hline NIHSS & $7.5(5-21)$ & $13(8-29)$ & 0.114 \\
\hline ICH score & $2(0-3)$ & $2(0-3)$ & 0.547 \\
\hline MAP [mmHg] & $115(98-128)$ & $117(103-140)$ & 0.120 \\
\hline Temperature $\left[{ }^{\circ} \mathrm{C}\right]$ & $37.0(36.4-37.4)$ & $36.8(36.1-37.3)$ & 0.200 \\
\hline Hemoglobin [mmol/l] & $8.26(7.45-9.00)$ & $8.38(7.70-9.38)$ & 0.351 \\
\hline Hematocrit & $0.383(0.342-0.420)$ & $0.396(0.370-0.428)$ & 0.288 \\
\hline Fibrinogen [mmol/l] & $10.58(8.91-11.94)$ & $9.85(8.29-11.03)$ & 0.103 \\
\hline HDL $[\mathrm{mmol} / 1]$ & $1.43(1.17-1.82)$ & 1.27 (1.04-1.59) & 0.043 \\
\hline $\mathrm{LDL}[\mathrm{mmol} / 1]$ & $3.07(2.73-3.82)$ & $3.15(2.50-4.16)$ & 0.855 \\
\hline Cholesterol [mmol/l] & $4.89(4.47-5.62)$ & $5.04(4.21-6.16)$ & 0.687 \\
\hline TAG [mmol/l] & $0.97(0.77-1.57)$ & $1.21(0.94-1.79)$ & 0.080 \\
\hline Cholinesterase $[\mathrm{kU} / \mathrm{l}]$ & $6.7(6.0-7.5)$ & $6.6(5.3-8.0)$ & 0.965 \\
\hline \multirow[t]{2}{*}{ Gamma GT [U/l] } & $27(19-43)$ & $29(18-68)$ & 0.279 \\
\hline & Mean, ( $($ SD) & Mean, ( $($ SD) & \\
\hline Leukocytes $\left[10^{\wedge} 9 / 1\right]$ & $10.3( \pm 4.3)$ & $11.3( \pm 10.5)$ & 0.444 \\
\hline $\mathrm{CRP}[\mathrm{mg} / \mathrm{l}]$ & $12.7( \pm 20.5)$ & $15.8( \pm 33.2)$ & 0.486 \\
\hline Thrombocytes $\left[10^{\wedge} 9 / 1\right]$ & $256( \pm 105)$ & $246( \pm 82)$ & 0.482 \\
\hline Glucose [mmol/l] & $7.44( \pm 2.78)$ & $7.66( \pm 2.89)$ & 0.623 \\
\hline HbA1c [\%] & $5.8( \pm 0.7)$ & $6.4( \pm 1.2)$ & 0.042 \\
\hline Creatinine $[\mu \mathrm{mol} / \mathrm{l}]$ & $85.0( \pm 24.8)$ & $105.3( \pm 123.9)$ & 0.165 \\
\hline Urea nitrogen $[\mathrm{mmol} / \mathrm{l}]$ & $12.78( \pm 6.68)$ & $13.82( \pm 6.89)$ & 0.328 \\
\hline
\end{tabular}


Figure 1.

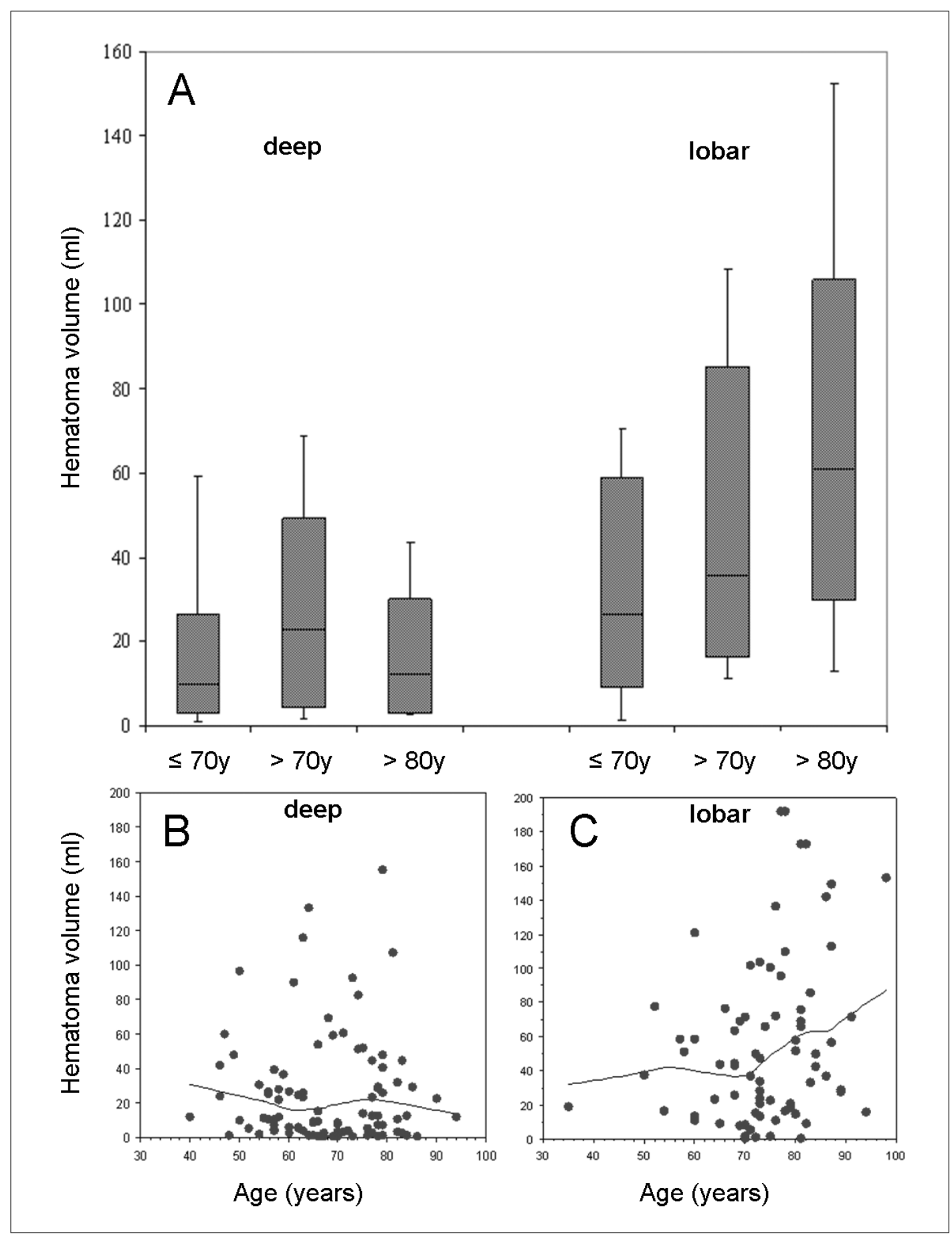


Table 3.

\begin{tabular}{llcl} 
Total & Lobar ICH & Deep ICH & $p$-value \\
$(\mathrm{n}=174)$ & $(\mathrm{n}=78)$ & $(\mathrm{n}=96)$ & \\
\hline
\end{tabular}

$\underline{\text { In-hospital treatment \& complications }}$

\begin{tabular}{|c|c|c|c|}
\hline DNT / DNR orders & $16(21.1 \%)$ & $14(14.6 \%)$ & 0.303 \\
\hline Ventilation & $26(33.3 \%)$ & $49(51.0 \%)$ & 0.015 \\
\hline Days of ventilation (median, IQR) & 0 (0-2) & $2(0-14)$ & 0.006 \\
\hline EVD & $10(12.8 \%)$ & $35(36.5 \%)$ & $<0.001$ \\
\hline Lumbar drainage & $3(3.8 \%)$ & $23(24.0 \%)$ & $<0.001$ \\
\hline Intraventricular lysis & $1(1.3 \%)$ & $22(22.9 \%)$ & $<0.001$ \\
\hline PEG tube placement & $9(11.5 \%)$ & $16(16.7 \%)$ & 0.330 \\
\hline Pneumonia & $30(38.5 \%)$ & $51(53.1 \%)$ & 0.049 \\
\hline Sepsis & $6(7.7 \%)$ & $19(19.8 \%)$ & 0.024 \\
\hline Length of stay [days] (mean, \pm SD) & $11.9( \pm 7.8)$ & $14.6( \pm 9.4)$ & 0.046 \\
\hline \multicolumn{4}{|l|}{ Outcome } \\
\hline In hospital mortality & $16(20.5 \%)$ & $18(18.8 \%)$ & 0.848 \\
\hline 90 day mortality & $21(26.9 \%)$ & $30(31.3 \%)$ & 0.617 \\
\hline 1 year mortality & $27(34.6 \%)$ & $38(39.6 \%)$ & 0.532 \\
\hline NIHSS at discharge (median, IQR) & $6.0(3-13)$ & $8.5(4-16)$ & 0.226 \\
\hline mRS 90day (median, IQR) & $4(3-6)$ & $5(3-6)$ & 0.587 \\
\hline mRS 90d (0-2) & $19(24.4 \%)$ & $21(21.9 \%)$ & 0.921 \\
\hline mRS 1 year (median, IQR) & $4(3-6)$ & $5(3-6)$ & 0.733 \\
\hline mRS 1y (0-2) & $25(32.1 \%)$ & $36(37.5 \%)$ & 0.700 \\
\hline Post stroke seizure & $22(28.2 \%)$ & $14(14.6 \%)$ & $\mathbf{0 . 0 2 8}$ \\
\hline History of EVD \& post stroke seizure & $5(22.7 \%)$ & $5(35.7 \%)$ & 0.462 \\
\hline
\end{tabular}


Table 4.

\begin{tabular}{|c|c|c|}
\hline Univariate variables & $\begin{array}{l}\text { Lobar ICH }(\mathbf{n}=78) \\
\text { Odds ratio }(95 \% \text { CI })\end{array}$ & $\begin{array}{l}p \text {-value } \\
(p<0.1)\end{array}$ \\
\hline \multicolumn{3}{|l|}{ a.) Demographics \& } \\
\hline \multicolumn{3}{|c|}{ Prior admission status \& past medical history } \\
\hline Age & $1.053(1.022-1.085)$ & 0.0006 \\
\hline Prior hemorrhagic stroke & $13.098(2.922-58.721)$ & 0.0008 \\
\hline \multicolumn{3}{|l|}{ b.) Radiologic data } \\
\hline Lesion volume $\left[\mathrm{cm}^{3}\right]$ & $1.019(1.010-1.028)$ & $<0.0001$ \\
\hline IVH & $0.362(0.195-0.673)$ & 0.0013 \\
\hline Graeb score & $0.796(0.722-0.878)$ & $<0.0001$ \\
\hline \multicolumn{3}{|l|}{ c.)Initial clinical presentation } \\
\hline MAP [mmHg] & $0.989(0.977-1.002)$ & 0.0979 \\
\hline \multicolumn{3}{|l|}{ d.) Laboratory parameters } \\
\hline $\mathrm{HbA1c}[\%]$ & $0.593(0.347-1.013)$ & 0.0558 \\
\hline $\mathrm{HDL}[\mathrm{mmol} / \mathrm{l}]$ & $1.029(1.004-1.055)$ & 0.0256 \\
\hline Gamma GT [U/l] & $0.534(0.281-1.012)$ & 0.0545 \\
\hline \multicolumn{3}{|l|}{ e.) Outcome\&Treatment } \\
\hline Length of stay [days] & $0.965(0.931-1.000)$ & 0.0489 \\
\hline Ventilation [days] & $0.499(0.268-0.927)$ & 0.0279 \\
\hline EVD & $0.256(0.117-0.561)$ & 0.0007 \\
\hline Lumbar drainage & $0.129(0.037-0.447)$ & 0.0013 \\
\hline Intraventricular fibrinolysis & $0.044(0.006-0.337)$ & 0.0026 \\
\hline Pneumonia & $0.556(0.300-1.030)$ & 0.0621 \\
\hline Sepsis & $0.348(0.131-0.921)$ & 0.0336 \\
\hline Post stroke seizures & $2.268(0.989-5.203)$ & 0.0532 \\
\hline
\end{tabular}


Table 5.

\begin{tabular}{|c|c|c|}
\hline Multivariate & $\begin{array}{l}\text { Lobar ICH }(\mathrm{n}=78) \\
\text { Odds ratio }(95 \% \mathrm{CI})\end{array}$ & $\begin{array}{l}p \text {-value } \\
(p<0.05)\end{array}$ \\
\hline \multicolumn{3}{|l|}{ a.) predictors } \\
\hline Age [years] & $1.065(1.001-1.132)$ & 0.0457 \\
\hline Prior ICH & $18.863(0.455-782.461)$ & 0.1222 \\
\hline Volume $\left[\mathrm{cm}^{3}\right]$ & $1.107(1.048-1.170)$ & 0.0003 \\
\hline IVH & $0.089(0.017-0.460)$ & 0.0039 \\
\hline Initial MAP [mmHg] & $1.002(0.972-1.033)$ & 0.8926 \\
\hline HbA1c [\%] & $0.402(0.189-0.855)$ & 0.0180 \\
\hline $\mathrm{HDL}$ [mmol/l] & $1.015(0.980-1.051)$ & 0.4088 \\
\hline \multicolumn{3}{|c|}{ b.) outcome \& treatment } \\
\hline Ventilation [days] & $1.815(0.543-6.069)$ & 0.3331 \\
\hline EVD & $0.200(0.040-0.992)$ & 0.0489 \\
\hline Pneumonia & $1.251(0.448-3.492)$ & 0.6686 \\
\hline Sepsis & $0.469(0.109-2.012)$ & 0.3079 \\
\hline Hospital stay [days] & $0.979(0.923-1.037)$ & 0.4665 \\
\hline Post stroke seizures & $2.844(1.059-7.640)$ & 0.0381 \\
\hline
\end{tabular}



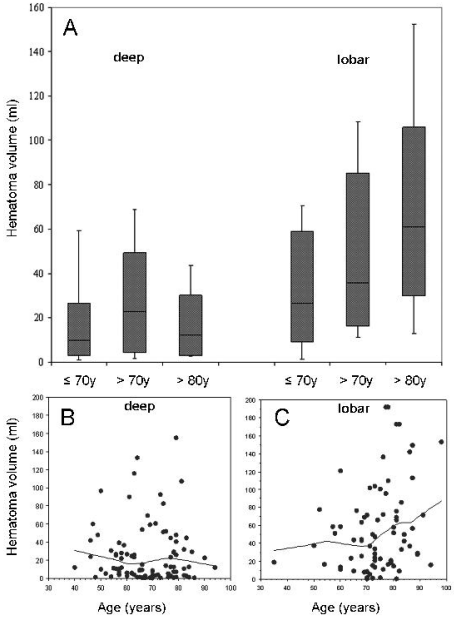